\title{
INOVAÇÃO DE PROCESSO EM UM CALL CENTER: DESAFIOS DE COLABORADORES EM UMA EMPRESA DE TV A CABO
}

\author{
https://dx.doi.org/10.48097/2674-8673.2022n6p09
}

\author{
Arandi Maciel Campelo ${ }^{1}$ \\ Everton Santana de Andrade ${ }^{2}$ \\ Lígia Amâncio da Silva ${ }^{3}$
}

\section{RESUMO}

Este artigo aborda conceitos sobre inovação, capacitação e motivação que gera a produtividade em uma empresa, retratando as dificuldades que os colaboradores enfrentam para conseguir se sobressair dos problemas, assim como as expectativas das organizações, mostrando a inovação de processo em um call center sobre as perspectivas dos colaboradores e os desafios que os mesmos enfrentam no dia a dia da empresa Cli-K. O estudo teve como objetivo identificar os principais pontos a serem melhorados quanto à inovação de processos no setor de serviços e na capacitação dos colaboradores, ressaltando o fator motivacional para conseguir alcançar a produtividade. O levantamento e análise foram realizados por meio da pesquisa de campo, através de um questionário fechado, aplicado entre 21 a 27/04/2021. Das 71 pessoas envolvidas, 55 (77\%) participaram do questionário. No contexto teórico, teve-se como base principal Chiavenato (2010). O estudo revelou o quão significante é a visão que os colaboradores possuem, pois atuam diretamente com os clientes na linha de frente enfrentando desafios, por isso é fundamental que as empresas invistam cada vez mais na inovação dos processos, na capacitação dos funcionários, dando importância ao fator motivacional para garantir a produtividade e bem estar de seus colaboradores.

Palavras-chave: Inovação de processo. Call Center. Desafios de colaboradores.

Data de submissão: $27 / 08 / 2021$

Data de aprovação: 20/10/2021

\begin{abstract}
This article addresses concepts about innovation, training and motivation that generate productivity in a company, portraying the difficulties that employees face to be able to stand out from the problems, as well as the expectations of organizations, showing process

\footnotetext{
${ }^{1}$ Orientador: Doutor em Educação - Universidade Federal de Pernambuco; Administrador - Universidade de Pernambuco - FCAP/UPE; Mestre em Planificación y Gestion Organizacional - Universidad Autonoma de Madrid / Espanha; Mestre em Dirección y Organización de Hospitales y Servicios de Salud - Universidad Politécnica de Valencia / Espanha; Especialista em Marketing - FCAP/UPE; Consultor em Sistemas Organizacionais, desde 1984; Professor e Diretor Acadêmico da Faculdade Metropolitana da Grande Recife. E-mail: arandi.campelo@globo.com ${ }^{2}$ Estudante do curso de Administração, da Faculdade Metropolitana da Grande Recife. E-mail: santana.everton005@gmail.com

${ }^{3}$ Estudante do curso de Administração, da Faculdade Metropolitana da Grande Recife.

E-mail: ligia.las@gmail.com
} 
innovation in a call center about the perspectives of employees and the challenges they face in the daily routine of the Cli-K company. The study aimed to identify the main points to be improved in terms of process innovation in the service sector and in employee training, highlighting the motivational factor to achieve productivity. The survey and analysis were carried out through field research, through a closed questionnaire, applied between 21 to 27/04/2021. Of the 71 people involved, $55(77 \%)$ participated in the questionnaire. In the theoretical context, the main basis was Chiavenato (2010). The study revealed how significant is the vision that employees have, as they work directly with customers on the front line, facing challenges, so it is essential that companies invest more and more in process innovation, in employee training, giving importance to the motivational factor to ensure the productivity and well-being of its employees.

Keywords: Process innovation. Call Center. Employee Challenges.

\section{REFERENCIAL TEÓRICO}

A inovação se constitui, hoje em dia, em uma estratégia essencial para o desenvolvimento de qualquer empresa, de qualquer porte. Enxergamos a inovação como símbolo de desenvolvimento e crescimento em um mercado cada vez mais competitivo. É comum, atualmente, que as empresas invistam em tecnologia, conhecimento e, acima de tudo, profissionais com perfil inovador.

A inovação pode se destacar de diversas formas, seja no produto, marketing, processos ou pessoas. A inovação de processos é de suma importância para a empresa que pretende se destacar dos seus concorrentes, uma vez que ela ganha mais flexibilidade e qualidade. Isso faz com que haja otimização do tempo de produção, garantindo maior eficiência e lucratividade.

Segundo Souza (2008), deve-se dar mais ênfase nas atividades que impactam no resultado final, seja um produto ou serviço, e não perder tempo com processos que não agregam valor ou resultado significativo.

\section{Inovação de processos no setor de serviços}

De acordo com Chiavenato (2010), a inovação tanto de processos quanto de produtos ou serviços traz ênfase à invenção e à aplicação, tornando-se como um apoio intensivo à qual se demonstra que as ideias inovadoras possibilitam melhoria contínua dentro das organizações.

Desta forma, é necessário ressaltar a importância da inovação nos processos de um Call Center, pois permite as correções de diversos problemas existentes dentro desse setor, sendo fundamental criar um clima organizacional que propicie a inovação, como:

a) Chamadas em espera que se refere à quantidade de consumidores que estão aguardando o atendimento. Falta de treinamento e feedbacks; 
b) Melhoria dos sistemas tecnológicos dos softwares, pois existem diversos sistemas para cada procedimento que reflete e muito nos indicadores;

c) Queda de ligação que causa insatisfação dos clientes e prejuízos para a empresa;

d) Tempo médio de atendimento que retrata o tempo de atuação de cada operador e o tempo médio de chamada que compreende desde o atendimento na URA (Unidade de Resposta Audível ${ }^{4}$ ) até a conclusão com o atendente.

Muitos colaboradores têm a percepção que é preciso às empresas desse ambiente inovar, justamente para evitar tantos transtornos que acabam resultando em enormes obstáculos dentro dessas organizações. Conforme descreveu Rissato (2004, p. 22): “O Call Center é o maior contribuinte para qualquer estratégia de marketing atual. A questão é que as empresas não aproveitam as informações que estão no Call Center para desenvolver suas estratégias".

Existem alguns fatores que contribuem para tal, porém é importante destacar os que mais favorecem para que as empresas consigam alcançá-los. Um fator determinante é a iniciativa de inovar, examinando as propostas que são consideráveis, controlando os seus efeitos e sempre fomentando para ter uma cultura inovadora. Outro ponto importante a respeito do assunto é justamente o de adotar medidas que viabilizem estratégias de negócios para aperfeiçoar os processos e oferecer ações que tenham planejamento que tragam mudanças positivas, pois é válido submeter uma empresa a ter um ambiente estruturado. É de extrema necessidade alcançar toda a esfera organizacional, ou seja, envolver todos os níveis de hierarquia, expandindo também para que chegue até os clientes, mantendo o foco no relacionamento com eles para fidelizá-los. Com isso é possível garantir, de forma satisfatória, o oferecimento dos serviços. Como apontou Davila, Epstein e Shelton (2007):

Organizar para a inovação continua a ser um desafio de grandes proporções para
muitas empresas. Não é suficiente desenvolver uma estratégia ou elaborar processos
de inovação; é indispensável construir e incutir a inovação no tecido geral da
organização. Inovação bem-sucedida exige escolher, elaborar e preparar a
organização adequada e as pessoas certas para executar e intensificar a inovação. (DAVILA; EPSTEIN; SHELTON, 2007, p. 104).

Deve-se levar em consideração que o setor de Call Center desempenha um papel essencial porque transmite um canal de interação entre a empresa e o usuário e que através dele os clientes podem fazer reclamações, elogios, esclarecer suas dúvidas, realizar compras ou cancelar, ou até mesmo fornecer sugestões de melhoria. Rissato (2004, p. 23) diz que "É fundamental gerar resposta do mercado por meio de estímulos eficazes e superar as expectativas do cliente quando ele bater à sua porta, seja por meio de um Call Center, da

${ }^{4}$ URA - Unidade de Resposta Audível: sistema de autoatendimento automático que permite a interação direta com o usuário por meio de menus preestabelecidos, recebendo comando e enviando informações. 
internet, seja pessoalmente". Visando esses aspectos, é necessário salientar a notoriedade dos benefícios que a inovação traz, contudo encontram-se alguns processos inovadores existentes dentro dos Call Centers, como a própria URA, Chat online, os Chatbots ${ }^{5}$ que integram as redes sociais (Instagram, Facebook, Linkedln, Twitter, You Tube e Whatsapp). Os operadores interagem e respondem aos usuários, sejam com mensagens prontas ou não, mas é preciso incorporar enriquecimento que incremente melhorias, pois muitos clientes ainda optam em realizar ligações por não conseguir o que deseja, seja por ter dificuldade de uso, por falhas dos sistemas ou por despreparo dos funcionários. A esse respeito, Rissato (2004) diz que "Na verdade, ninguém deve implantar um CRM (Customer Relationship management), mas sim melhorar os processos no relacionamento com seus Clientes. A tecnologia, o software, deve ajudá-lo no processo, e não o contrário".

\section{Capacitação de colaboradores no segmento de serviços}

Sem sombra de dúvida, é nítido que cada colaborador seja uma peça-chave para uma boa produtividade na empresa ou na prestação de serviços, porém para que as atividades sejam exercidas de forma eficiente e eficaz é necessário que passem por capacitações para que estejam aptos no desenvolvimento de suas atividades. Segundo Marras (2000), o treinamento produz um estado de mudança no conjunto de conhecimentos, habilidades e atitudes de cada colaborador, uma vez que o programa modifica a bagagem particular de cada um. Por isso, é de grande relevância capacitar os colaboradores para evitar situações que os mesmos não consigam resolver, seja por não terem conhecimento ou por não se sentirem confiante o suficiente.

Para Chiavenato (2010, p. 367), “através do treinamento - e do desenvolvimento -, a pessoa pode assimilar informações, aprender habilidades, desenvolver atitudes e comportamentos diferentes e desenvolver conceitos abstratos". Portanto, é conveniente orientá-los para que saibam qual linguajar usar ou qual postura adotar, pois irão lidar com diversas personalidades e tipos de clientes. Pessoas bem treinadas muitas vezes desenvolvem estratégias e habilidades que ajudam bastante na resolução dos processos. Por esse motivo torna-se essencial às organizações estarem engajadas a darem espaços para que os funcionários possam adquirir conhecimento e aplicá-los.

Mancini (2006) sintetiza a questão de capacitação de operadores afirmando que

\footnotetext{
${ }^{5}$ Um Chatbot é um software capaz de manter uma conversa com um usuário humano em linguagem natural, por meio de aplicativos de mensagens, sites, e outras plataformas digitais.
} 


\begin{abstract}
O bom atendimento é construído sobre bons processos [...] o sucesso depende de um conjunto de atributos, que começa pela definição estratégica que orientará todas as ações da empresa em relação aos seus clientes, fornecedores e colaboradores internos [...] processos de integração entre departamentos, trânsitos e circulação das informações, implantação de ações baseadas nessas informações e seu gerenciamento para produzir satisfação, eficiência e fidelização. Fundamental neste processo é a capacitação do pessoal linha de frente, do operador que estará em contato direto com o cliente, com o prospect $^{6}$ (cliente em potencial) ou usuário, pois as mídias eletrônicas ainda não criaram um ambiente de interatividade total para atender pedidos, aceitar perguntas, críticas, sugestões etc.. (MANCINI, 2006, p. 76).
\end{abstract}

Tachizawa et al. (2006) salientaram que investir no desenvolvimento das pessoas que realizam o trabalho nas organizações significa investir na qualidade dos produtos e serviços e, consequentemente, atender melhor os clientes e ampliar as vendas. Desse modo, é possível perceber o quão significativo são os conceitos a respeito da capacitação dos profissionais, sendo essencial investir em treinamento, orientando os funcionários a seguir a política da empresa, trazendo ações que possibilitem que os mesmos se desenvolvam. Por essa razão é de extrema urgência que as organizações tenham o desejo de investir na capacitação dos profissionais porque assim irão conseguir assegurar o retorno que almejam, ampliando o conhecimento dos colaboradores para que apresentem os produtos ou serviços com total confiança.

Torquato e Toledo (2016) falam da importância de não somente planejar, mas também ter um conceito a respeito das principais concepções que orientam as empresas a terem um dimensionamento, fazendo referências as estruturas oferecidas pelas organizações em processos de capacitação de seus profissionais. Marras (2000) apontou que através de programas de treinamento e de desenvolvimento a empresa deverá buscar e criar as competências necessárias para esse desenvolvimento do trabalho e assim gerar o resultado esperado através das competências a serem desenvolvidas. Lamentavelmente, muitas empresas cobram de seus funcionários produtividade, qualidade na prestação de serviço, exigem que as metas estabelecidas sejam alcançadas, mas não dão um treinamento capacitando o funcionário de como e quando devem agir para alcançar tais resultados. A falta desse suporte acaba gerando insatisfação por parte dos colaboradores.

Para Reginatto (2004), o treinamento ajuda as pessoas a serem mais eficientes, evitando erros, melhorando atitudes e alcançando maior produtividade. Por meio dele pode-se aprender fazendo, reavaliando e mudando comportamentos. Mas como capacitar de forma adequada os colaboradores de Call Center? Independente das circunstâncias que existem ou que possam existir, é fundamental buscar alternativas que ultrapassem os obstáculos porque não adianta

\footnotetext{
${ }^{6}$ Um prospect é um potencial cliente qualificado, que deve se adequar a certos critérios .
} 
realizar diversas demandas de treinamentos e não colher os frutos desejados. Desse modo, é preciso enfatizar alguns pontos relevantes que evidenciam a obter melhores resultados:

a) Estimular uma cultura de inovação que dissemine o conhecimento, valores e políticas da empresa, buscando os perfis corretos que se encaixe no processo apresentado;

b) Identificar os problemas, planejar, sanar e coletar informações através de entrevistas ou questionários que identifiquem os principais gargalos que necessitam ser tratados;

c) Avaliar os resultados sempre verificando a relação entre os custos e os benefícios, se a empresa obteve retorno, agregou valor ou conseguiu aumentar a produtividade;

d) Controlar os processos, analisando a melhor maneira possível de orientar os funcionários a atender os clientes;

e) Orientar os funcionários para que ofereçam um atendimento humanizado e que adotem boas práticas tendo empatia, boa comunicação, utilizando os nomes dos clientes ao se reportar para eles. Devem-se deixar de lado os famosos scripts, evitando padronizações.

A capacitação de serviços requer processos que projetem, apliquem e aperfeiçoem. Medidas como essas fazem com que as organizações desse segmento cheguem a um patamar favorável de resultados precisos, estruturado e, principalmente, a um desenvolvimento contínuo de seus funcionários. Pacheco et al. (2005, p. 18) citam que "o treinamento profissional diz respeito à preparação do indivíduo, com a assimilação de novos hábitos, conhecimento, técnicas e práticas voltadas para a satisfação de demandas no exercício da profissão". Alguns funcionários das empresas de Call Centers em estudo demonstraram aparentemente estarem insatisfeitos com o trabalho que desempenham, pois estão sempre reclamando sem motivos. Além de reclamarem do serviço, não dão ouvidos quando seus supervisores tentam resolver a situação. Schaufeli, Dijkstra e Vazquez (2013) ressaltam que:

\footnotetext{
É possível encontrar pessoas com pouco entusiasmo para realizar as coisas. Elas não são engajadas e, definitivamente, não são viciadas em trabalho. Algumas pessoas trabalham em atividades que não gostam e se sentem entediadas ou infelizes por isso; o dia de trabalho parece durar para sempre e elas se arrastam de um intervalo no trabalho para o outro porque não se sentem desafiadas pelas atividades que realizam. (SCHAUFELI; DIJKSTRA; VAZQUEZ, 2013, p. 24).
}

\section{Motivação e produtividade}

A motivação é algo individual, ninguém motiva ninguém, ela é interna. Gestores ou líderes podem realizar ações de estímulos, desencadeando o grau de satisfação dos indivíduos consigo mesmo. No entanto, existe um elo entre a motivação e a produtividade que para obter faz-se necessário promover ações inovadoras que levem as pessoas a se motivarem. 
Sobretudo, é preciso incentivá-las provocando a motivação. Chiavenato (2010) destacou como um dos maiores objetivos a serem alcançados pelas organizações, justamente o de tentar motivar as pessoas, fazê-las decididas, confiantes e comprometidas a atingir o que thes forem propostos. Campelo (2014) retratou como um grande desafio para nossa evolução a dificuldade de lidar e compreender o comportamento das pessoas com dois sentidos opostos: pode ser algo maravilhoso e gratificante, porém bastante intenso e desafiador. Um colaborador motivado produz mais em pouco tempo porque almeja demonstrar seu desempenho seja para obter um crescimento ou um reconhecimento dentro da empresa ou até mesmo receber uma bonificação pela sua produtividade. Enquanto que um funcionário desmotivado costuma causar conflitos porque adota uma postura descomprometida, não se empenha em atingir os objetivos propostos pela organização, deixando de atender as solicitações, ou até mesmo prestando um atendimento de baixa qualidade, tratando os clientes com descaso, além de afetar também seus colegas, contagiando-os ou induzindo-os a seguir o seu exemplo.

As organizações devem compreender a necessidade de dar atenção especial ao fator motivacional para obterem produtividade. Conforme Chiavenato (2010, p. 2421) "A motivação é um processo psicológico básico. Juntamente com a percepção, atitudes, personalidade e aprendizagem, a motivação sobressai como um importante processo na compreensão do comportamento humano". Entretanto, existem alguns pontos importantes a serem organizados pelas empresas, em todos os níveis de hierarquia. Proporcionar estratégias inovadoras que possam sair do plano e serem executadas, estabelecendo indicadores que permitam alguns elementos específicos que propiciam a motivação e produtividade, tais como reconhecimento, agradecimentos, realização de eventos comemorativos, um lembrete do aniversário do profissional, brindes, bonificações e aceitar sugestões dos colaboradores. Torna-se nítido que as organizações desejam que os seus colaboradores executem o que lhe foi solicitado, contudo é necessário criar uma estrutura que retrate um ambiente apropriado para isso. Bes e Capaverde (2019) mencionam que:

\footnotetext{
Para que uma organização realize o que se propõe a fazer, seja na prestação de um serviço ou na produção de algum bem, precisa, obrigatoriamente, de uma estrutura adequada e de um esforço ordenado na utilização de seus recursos tangíveis e intangíveis. Assim, as pessoas despontam na atualidade como o principal ativo capaz de levar a organização a atingir os seus objetivos. Porém, uma organização é complexa, e a forma como ela se estrutura produz determinado sentimento entre as pessoas que a integram. (BES; CAPAVERDE, 2019, p. 60).
}

Há diversas vantagens para as empresas que oferecem um ambiente pertinente para que pessoas se motivem, então é imprescindível traçar objetivos que estimulem os 
colaboradores a sentir essa sensação. Buscar procedimentos que promovam uma cultura organizacional transparente, realizar feedback não somente para apontar as falhas, mas para enriquecer o conhecimento dos funcionários, indicando o caminho certo, tendo essa interação para converter em uma maneira infalível que permita aumentar a produtividade e executar atividades que envolvam a equipe em busca de soluções, respeitando o desempenho de cada um. Tadeucci (2020) reforça a necessidade de ter um ambiente adequado para os colaboradores ao citar que:

O funcionário precisa de um ambiente propício para demonstrar sua capacidade de realização da tarefa. Uma máquina quebrada, instrumentos e ferramentas obsoletas levam à baixa produtividade e consequentemente a desmotivação. As condições de higiene do espaço físico de trabalho, alimentação, pausas para repouso todos esses aspectos interferem no nível de motivação. (TADEUCCI, 2020, p. 72).

De maneira geral, torna-se oportuno acolher as queixas dos funcionários para promover condições necessárias que desenvolvam práticas integradas, assim permitindo chegar ao nível motivacional e percorrer em melhores resultados que refletem na produtividade também. Portanto, para que haja um equilíbrio é preciso simplificar os processos que dificultam a atuação da equipe, pois a produtividade elevada conduz a motivação a um crescimento.

Tadeucci (2020) acentuou alguns aspectos que interferem na motivação, tais como:

a) O que é preciso fazer para que as pessoas despertem interesses que as levem ao fator motivacional?

b) Quais são os seus desejos?

c) O que elas consideram como uma boa recompensa?

São pontos que simplificam a necessidade de compreender e abordar soluções que viabilizem um dimensionamento que facilite o autoconhecimento e as relações interpessoais, focando nos pontos como esses para obter o alcance das metas estabelecidas porque o trabalho é desgastante. Não é fácil lidar diariamente com uma variedade de personalidades de diversos clientes, com várias cobranças internas, além dos problemas que surgem externamente, fora das organizações, como os pessoais. Então é válido que os gestores das empresas de Call Centers se preocupem com a motivação não somente como um todo, no coletivo, mas também individualmente, e realizem campanhas bem qualificadas que envolvam os colaboradores a ter interesse de participar e de exercer um bom desempenho, desse modo irão obter a produtividade desejada. Segundo Tadeucci (2020, p. 18), "as pessoas podem ter resultados mais gratificantes, ou não, em suas metas e objetivos pessoais, à medida que se sentirem mais motivadas, capazes, e tiverem condições em seu ambiente para atingir as suas expectativas". 
Criar desafios é a proposta mais comum dentro de uma operação de Call Center. É necessário reconhecer o trabalho, elogiar o desempenho, seja individual ou da equipe, e escutar os profissionais.

\section{METODOLOGIA}

Este artigo está embasado em uma pesquisa bibliográfica e de campo, com a finalidade aplicada, com método de análise propositiva e abordagem qualitativa, com coleta de dados por meio de um questionário fechado constante no apêndice.

O campo investigativo foi no Grupo Cli-K Telecom ${ }^{7}$, em Recife. O universo foi de 71 colaboradores, sendo 2 analistas de recursos humanos, 6 supervisores administrativos, 4 supervisores operacionais e 59 operadores. Destes, 55 participaram, ou seja, uma amostra de $77 \%$, com um erro amostral de $23 \%$.

\section{DESENVOLVIMENTO DA PESQUISA DE CAMPO}

Quais formas a empresa possui que contribuem para uma cultura organizacional inovadora?

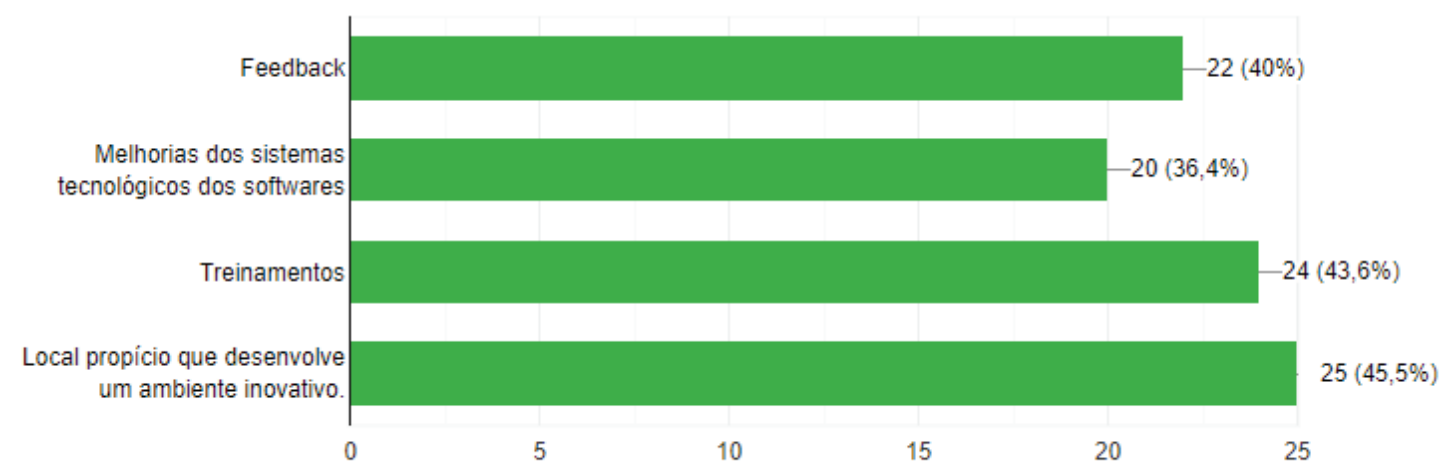

Nesta questão, 43,6\% dos inquiridos afirmaram que o treinamento é uma das principais estratégias para se criar um ambiente inovador na organização, algo bastante compatível com o que foi afirmado por Davila, Epstein e Shelton (2007), demonstrando, portanto, o valor e força que a capacitação de funcionários tem na elevação de uma cultura inovadora de atuação.

\footnotetext{
${ }^{7}$ Campo investigativo: Grupo Cli-k Telecom. Ano de fundação/criação: 2008. Mercado de atuação: Call Center. Localização: Rua Gervário Pires, N²34, Sala 101, Boa Vista, Recife - PE.
} 
Existem práticas utilizadas pela empresa que estimule a inovação?
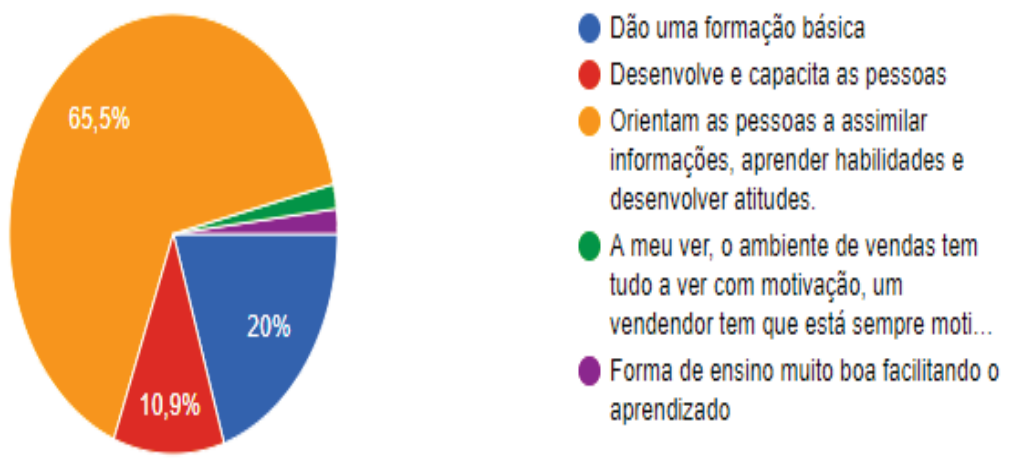

$65,5 \%$ dos inquiridos informaram o quão importante é orientar as pessoas para que a empresa consiga um ambiente que estimule a inovação, algo semelhante ao que Chiavenato (2010) apresentou. Ressalta-se também a necessidade de desenvolver para que elas assimilem, aprendam habilidades e comportamentos diferentes.

Justifique a sua escolha referente à resposta da questão anterior ou cite alguma sugestão:

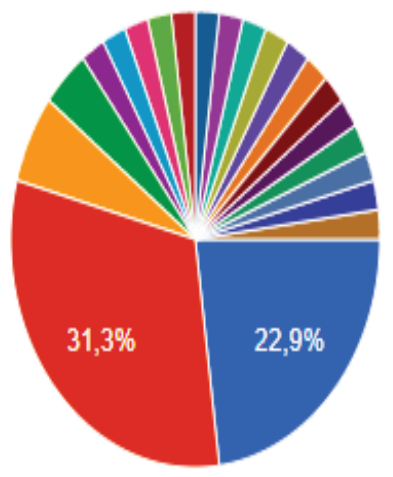

Justifique sua resposta

Sugestão

Existe um período de treinamento ond..

Fazem dinâmicas interessantes que e...

Desenvolve os colaboradores nas sua..

acredito que há mais formas de agreg..

Ensinam as técnicas de vendas e co...

Com treinamentos

A $1 / 3$

Nesta questão, 31,3\% dos respondentes salientaram que é preciso a empresa adquirir novas ideias para criar um ambiente que estimule a inovação, paralelo ao que citou Tadeucci (2020). É importante promover ações que contribuam para obter um local propício à inovação. 
Encontra-se algum controle de proteção para evitar que uma ideia inovadora seja copiada por outra empresa?

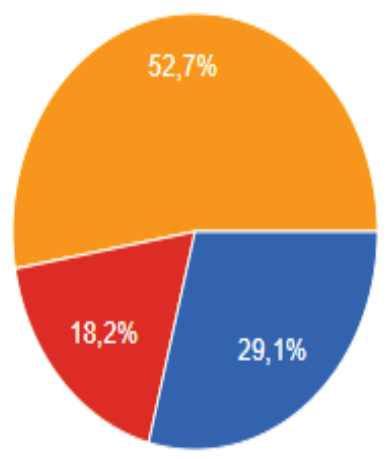

Existe um controle, mas não evita que as ideias sejam copiadas.

Não existe nenhum controle

A empresa adota medidas de controle e de proteção de forma eficiente

$52,7 \%$ dos inquiridos ressaltaram a relevância em relação a proteger uma ideia inovadora, correspondente ao que mencionaram Bes e Capaverde (2019), destacando, contudo, a forma como a empresa se estrutura para garantir o que se propõe.

A empresa possui programas de capacitação ou qualificação profissional?

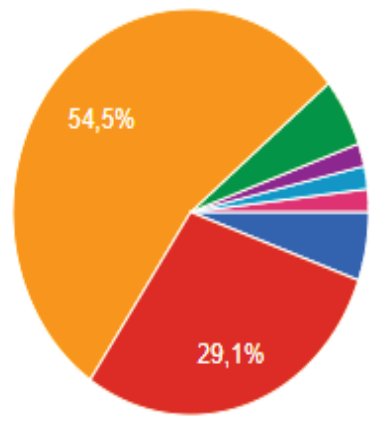

Sim, investe na capacitação dos profissionais

Possuem programas de treinamento e de desenvolvimento

Direciona um caminho que garante qualidade, eficiência e produtividade

Não há programas de capacitação ou...

Nao tem nenhum curso de capacitação

Não, que eu saiba.

Treinamento teórico e prático.

$54,5 \%$ dos participantes afirmaram como são preciosos os programas de capacitação e qualificação profissional, pois garantem um caminho de qualidade e eficiência, resultando na produtividade, conciliável com que foi citado por Marras (2000).

Existe algum ambiente dentro da empresa que propicie os colaboradores a se motivarem?

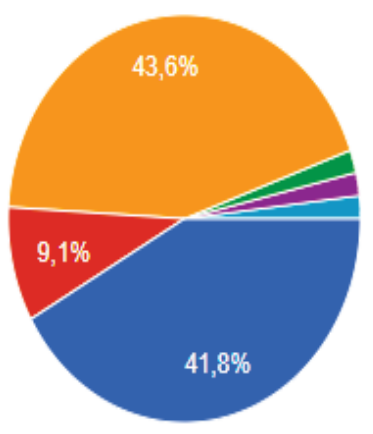

Existem eventos comemorativos

A empresa realiza feedbacks diários

Os gestores elogiam o desempenho dos colaboradores

todas as alternativas acima

Festa de final de ano

Campanhas semanais 
Torna-se nítida a visão que os inquiridos possuem referente ao fator motivacional, pois $43,6 \%$ demonstraram a necessidade da existência de eventos comemorativos, enquanto 41,8\% ressaltaram a importância dos gestores elogiarem o desempenho dos funcionários, algo bastante semelhante com que foi retratado por campelo (2014).

Os operadores possuem autonomia para tomar decisões durante o atendimento ou para realizar um atendimento humanizado?

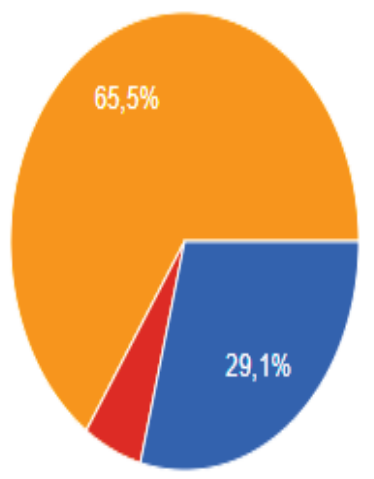

Sim, existe atendimento humanizado e os operadores recebem autonomia para tomar decisões.

Os operadores não possuem nenhuma autonomia no atendimento

Existe um controle quando às tomadas de decisões, porém os operadores possuem autonomia no atendimento humanizado

Nesta questão, 65,5\% dos entrevistados afirmaram a relevância de terem autonomia durante o atendimento, recebendo apoio de seus superiores, paralelo com o que sintetizou Mancini (2006). É fundamental essa autonomia dos operadores nas tomadas de decisões durante os atendimentos, pois eles são o pessoal da linha de frente.

Existem faixas salariais diferenciadas conforme habilidade ou produtividade dos colaboradores?

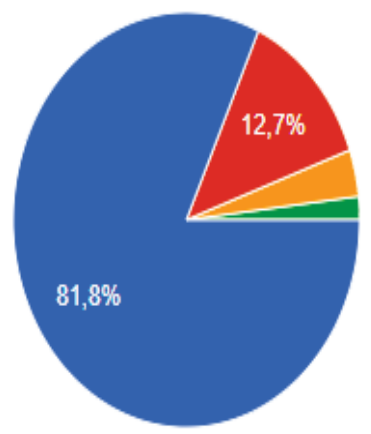

Sim, de acordo com a produtividade

Não existe

Existe para quem possui habilidade

Salário é igual, mais tem comissão para os melhores resultados.

$81,8 \%$ dos inquiridos informaram a importância de premiar os colaboradores conforme suas habilidades e produtividade, semelhante ao que citou Tadeucci (2020) a respeito dos fatores que contribuem para que os colaboradores alcancem suas expectativas. 
A empresa adota alguma rotina de trabalho que propicie os funcionários a captar informações importantes para a inovação?

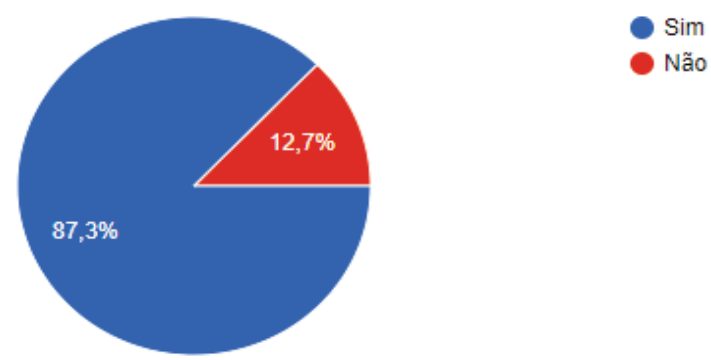

Nesta questão, 87,3\% dos participantes afirmaram que é preciso as empresas possuírem uma rotina de trabalho que vise captar informações pertinentes à inovação, compatível com o que foi citado por Chiavenato (2010). Por isso, faz-se necessário criar uma rotina de trabalho que propicie a inovação, pois irá possibilitar melhoria contínua dentro da empresa.

Os colaboradores recebem remuneração extra pelo seu desempenho ou produtividade?
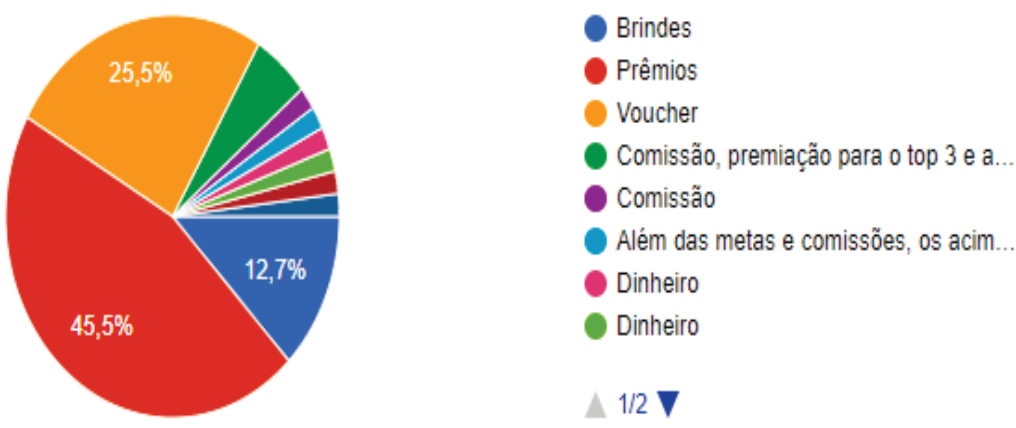

$45,5 \%$ dos participantes pontuaram a necessidade das empresas adotarem campanhas que realizem remuneração extra, seja pelo desempenho ou pela produtividade, paralelo ao que mencionou Tadeucci (2020), ressaltando o fator remuneração. Isso acaba gerando motivação, um ótimo desempenho e uma boa produtividade.

Existe reconhecimento por partes dos gestores?
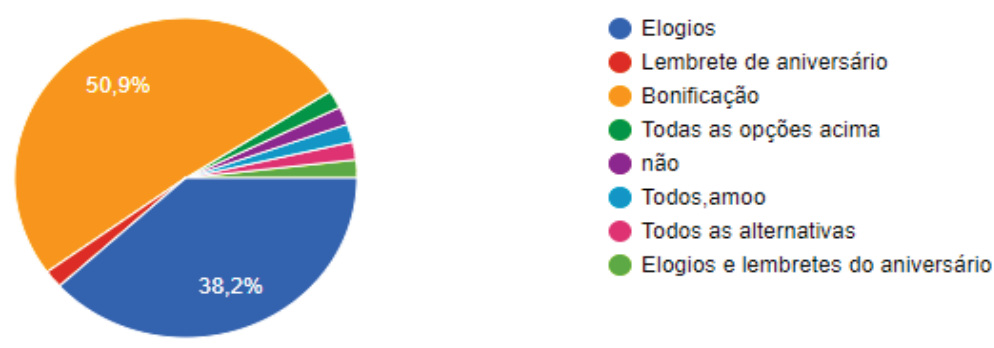
$50,9 \%$ dos participantes destacaram o quão significante são as medidas que viabilizem o reconhecimento. Schaufeli, Dijkstra e Vasquez (2013) reforçaram essa ideia, afirmando que é muito importante realizar processos que foquem no fator motivacional, abordando ideias engajadas que contribuam para reconhecer as pessoas em seu local de trabalho.

Os gestores aceitam ou acatam sugestões dos colaboradores?

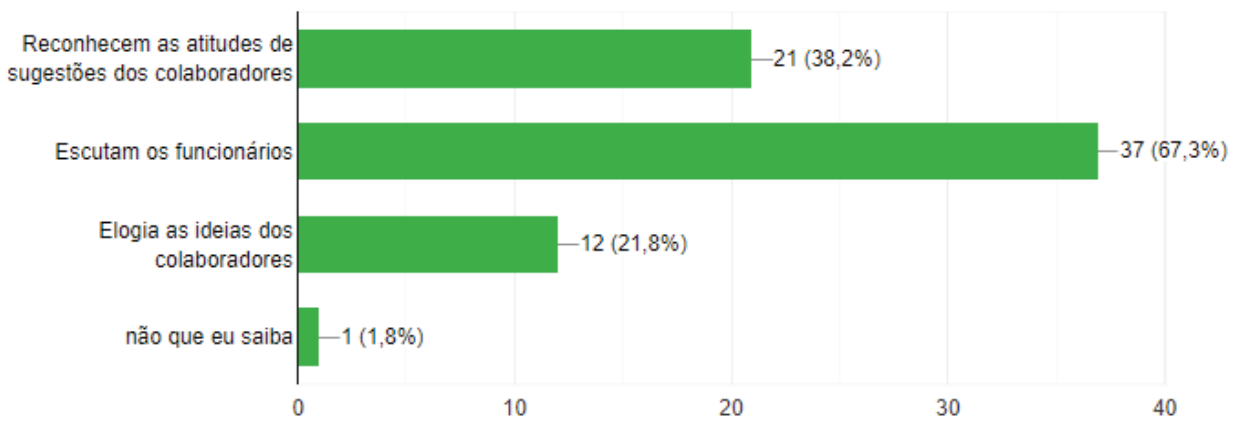

$67,3 \%$ dos inquiridos afirmaram a importância dos gestores ouvirem os seus colaboradores, algo bem compatível com o que foi abordado por Rissato (2004). Torna-se evidente o quão relevante é o fato dos gestores escutarem seus funcionários, pois dentro do Call Center, os que mais recebem informações são os colaboradores, logo é necessário saber aproveitar essas informações e transformá-las em estratégias.

\section{CONSIDERAÇÕES FINAIS}

Este artigo buscou identificar e analisar os principais problemas existentes dentro de um Call Center, através da visão dos colaboradores, e assim contribuir para que existam melhorias dentro desse segmento. Foi possível identificar e observar o quão essencial foram os resultados obtidos e como eles podem contribuir para pesquisas futuras, servindo como base para as demais pessoas que necessitem se aprofundar e ampliar os seus conhecimentos. A empresa analisada em Recife - PE, Cli-K, tem um papel relevante, pois visa alcançar um processo inovativo e, assim, entender e analisar as expectativas de seus colaboradores. A pesquisa ressalta o quão significante é a participação dos colaboradores para uma melhor compreensão sobre os métodos que devem ser utilizados para obter uma excelente resolução.

Diante do que foi analisado, recomenda-se caminhos a serem seguidos para obter êxitos na inovação de processos em um Call Center, ressaltando pontos fundamentais de melhorias na capacitação e no fator motivacional dos colaboradores que atuam em um na empresa pesquisada, tais como: implantação de programas de capacitação e treinamento para desenvolver os funcionários, realizando feedback construtivos para entendê-los e assim 
orientá-los da melhor forma possível, utilizando métodos que façam com que os colaboradores interajam, e com isso se motivem a querer participar, através de algumas ações, um simples elogio, premiações, bonificações ou campanhas bem estruturadas que despertem o comprometimento de todos para conseguir alcançar a produtividade dos funcionários, destacando também um local propício para a inovação.

\section{REFERÊNCIAS}

BES, Pablo; CAPAVERDE, Caroline Bastos. Planejamento em gestão de pessoas. Porto Alegre: SAGAH, 2019.

CAMPELO, Arandi Maciel. Gestão de pessoas: compreendendo o comportamento humano nas organizações. 6. ed. Recife: FCAP Books, 2014.

CHIAVENATO, Idalberto. Gestão de pessoas. 3. ed. Rio de Janeiro: Elsevier, 2010.

. Comportamento organizacional: a dinâmica do sucesso das organizações. 3 . ed. Rio de Janeiro: Elsevier, 2010.

DAVILA, Tony; EPSTEIN, Marc J.; SHELTON, Robert. As regras da inovação: como gerenciar, como medir e como lucrar. Porto Alegre: Bookman, 2007.

Guia Completo. Chatbots: o que é, como funciona, benefícios e cases. Disponível em: HTTPS://take.net/blog/chatbots/chatbot. Acesso em: 01 nov. 2020.

MARRAS, Jean Pierre. Administração de recursos humanos: do operacional ao estratégico. 14. ed. São Paulo: Saraiva, 2011.

MANCINI, Lucas. Call Center: estratégia para vencer. 2. ed. São Paulo: Summus Editorial, 2006.

PACHECO, Luiza et al. Capacitação e desenvolvimento de pessoas. Rio de Janeiro: Ed. FGV, 2005.

REGINATTO, Antonio Paulo. Equipes campeãs: potencializando o desempenho de sua equipe. 2. ed. Porto Alegre: Ed. SEBRAE/RS, 2004.

RISSATO, Marcelo. O cliente por um fio: o que você precisa saber sobre marketing e Call Center. São Paulo: Nobel, 2004.

SCHAUFELI, W. B.; DIJKSTRA, P.; VAZQUEZ, A. C. O engajamento no trabalho. São Paulo: Ed. Casa do Psicólogo, 2013.

SOUZA, Balzani. Gestão de processos. v. 4. Paraná, (PR): Sebrae, 2008.

TADEUCCI, Marilsa de Sá Rodrigues. Motivação e liderança. Curitiba: Ed. Brasil S. A., 2011. 
TACHIZAWA, Takeshy et al. Gestão com pessoas: uma abordagem aplicada às estratégias de negócios. 5. ed. Rio de Janeiro: FGV, 2006.

TIDD, Joe; BESSANT, John. Gestão da inovação. 5. ed. Porto Alegre: Bookman, 2015.

TORQUATO, Diomar Pedro; TOLEDO, Jair Fiuza. Descomplicando as telecomunicações nas empresas: Dimensionamento e métricas em PABX e Call Centers. São Paulo: Laços Ltda., 2016.

\section{APÊNDICE A - Modelo do instrumento de coleta de dados e informações}

1. Quais formas a empresa possui que contribuem para uma cultura organizacional inovadora?

02. Existem práticas utilizadas pela empresa que estimule a inovação?

03. Justifique a sua escolha referente à resposta da questão anterior ou cite alguma sugestão:

04. Encontra-se algum controle de proteção para evitar que uma ideia inovadora seja copiada por outra empresa?

05. A empresa possui programas de capacitação ou qualificação profissional?

06. Existe algum ambiente dentro da empresa que propicie os colaboradores a se motivarem?

07. Os operadores possuem autonomia para tomar decisões durante o atendimento ou para realizar um atendimento humanizado? conforme a habilidade ou produtividade dos colaboradores?

09. A empresa adota alguma rotina de trabalho que propicie os funcionários a captar informações importantes para a inovação?

10. Os colaboradores recebem remuneração extra pelo seu desempenho ou produtividade?

11. Existe reconhecimento por partes dos gestores?

12. Os gestores aceitam ou acatam sugestões dos colaboradores? (a) Feedbacks. (b) Melhorias dos sistemas tecnológicos dos softwares. (c) Treinamento. (d) Local propício que desenvolve um ambiente inovativo. (e) Outros.

(a) Dão uma formação básica. (b) Desenvolve e capacita às pessoas. (c) Orientam as pessoas a assimilar informações, aprender habilidades e desenvolver atitudes. (d) Outros.

(a) Justificativa: (b) Sugestão:

(a) Existe um controle, mas não evita que as ideia sejam copiadas. (b) Não existe nenhum controle. (c) A empresa adota medidas de controle de proteção de forma eficiente. (d) outros

(a) Sim, investe na capacitação dos profissionais. (b) Possuem programas de treinamento e de desenvolvimento. (c) Direciona um caminho que garante qualidade, eficiência e produtividade. (d) Outros.

(a) Existem eventos comemorativos. (b) A empresa realiza feedbacks diários. (c) Os gestores elogiam o desempenho dos colaboradores. (d) Outros

(a) Sim, existe atendimento humanizado e os operadores possuem autonomia para tomar decisões. (b) Os operadores não possuem nenhuma autonomia no atendimento. (c) Existe um controle quanto às tomadas de decisões, porém os operadores possuem autonomia para realizar um atendimento humanizado. (d) Outros

(a) Sim, de acordo com a produtividade. (b) Não existe. (c) Existe para quem possuem habilidades. (d) Outros.

(a) Sim. (b) Não.

(c) Sugestão

(a) Brindes. (b) Prêmios. (c) Voucher. d) Outros

(a) Elogios. (b) Lembrete de aniversário. (c) Bonificação (d) Outros.

(a) Reconhecem as atitudes de sugestões dos colaboradores.

(b) Escutam os funcionários. (c) Elogia as ideias dos colaboradores. (d) Outros 